\title{
Population Dynamics of Scytalidium thermophilum in Mushroom Compost and Stimulatory Effects on Growth Rate and Yield of Agaricus bisporus
}

\author{
By GERBEN STRAATSMA, ${ }^{1 *}$ JAN P. G. GERRITS, ${ }^{1}$ \\ MARC P. A. M. AUGUSTIJN, ${ }^{2}$ HUUB J. M. OP DEN CAMP, ${ }^{2}$ \\ GODFRIED D. VOGELS ${ }^{2}$ AND LEO J. L. D. VAN GRIENSVEN ${ }^{1}$ \\ ${ }^{1}$ Mushroom Experimental Station, Postbus 6042, 5960 AA Horst, The Netherlands \\ ${ }^{2}$ Department of Microbiology, University of Nijmegen, Toernooiveld, 6525 ED Nijmegen,
}

The Netherlands

(Received 28 June 1988; revised 18 November 1988; accepted 8 December 1988)

\begin{abstract}
Mycelial growth of Agaricus bisporus on sterilized compost is strongly stimulated by preincubating the compost with the thermophilic fungus Scytalidium thermophilum. This stimulatory effect is not species specific, for either $A$. bisporus or $S$. thermophilum. Normal mushroom compost is almost completely colonized with $S$. thermophilum. In experimental composts a positive relation was found between the logarithm of mushroom yield of $A$. bisporus and the density of $S$. thermophilum. $S$. thermophilum provides for compost selectivity: it protects against negative effects of compost bacteria on mycelial growth of $A$. bisporus. S. thermophilum is inactivated by the growth of $\boldsymbol{A}$. bisporus mycelium.
\end{abstract}

\section{INTRODUCTION}

The edible white button mushroom Agaricus bisporus (Lange) Imbach is cultivated in the western hemisphere on a substrate consisting of a composted mixture of horse manure, wheat straw, chicken manure and gypsum. Conventionally two composting phases are distinguished (Sinden \& Hauser, 1950; Fermor et al., 1985). Phase I is an outdoor fermentation process during which $\mathrm{NH}_{3}$ and unpleasant-smelling compounds are emitted into the environment. Phase II is an indoor process of pasteurization followed by conditioning at approximately $45^{\circ} \mathrm{C}$. This can either be performed in limited quantities in mushroom houses or in bulk in 'tunnels'. In mushroom houses self-heating of the compost is controlled by ventilating air around layers of up to $30 \mathrm{~cm}$ thick contained in trays or beds. In tunnels air is forced through the body of the compost, allowing a more accurate control, and layers up to $250 \mathrm{~cm}$ can be processed (Derks, 1973; Gerrits, 1988a).

If phase I were carried out indoors waste air could be treated before discharge, preventing the release of ammonia. A combined phase I and phase II indoor process as introduced by Lambert (1941) could prevent further environmental problems as preliminary results of our group P. J. L. Derikx, personal communication) indicate that the release of fetid volatiles is prevented in phase II carried out in tunnels. Recent experiments suggest that combined phase I and phase II indoor composting is feasible (Laborde et al., 1987; Perrin \& Gaze, 1987; Gerrits, 1987). Perrin \& Gaze (1987) and Gerrits (1987) processed raw moistened materials in tunnels and followed phase II procedures only. Good mushroom yields were obtained.

The basic nutritional requirements of $\boldsymbol{A}$. bisporus in vitro are already known (Wood \& Fermor, 1985 ) and easily met by compost. However, successful colonization and use of compost by $A$. bisporus depends strongly on ecological properties, usually referred to as 'compost selectivity'. It is largely unknown how selectivity can be described in chemical or biological terms. Obviously the rate of substrate colonization during the vegetative phase of mushroom culture is important. 
In earlier research on $A$. bisporus, mycelial growth was studied in tubes filled with substrate. No exact growth rates were published until Sinden (in Tschierpe, 1983) reported linear growth of about $9 \mathrm{~mm} \mathrm{~d}^{-1}$. Growth of $A$. bisporus was reduced to 'half' by sterilization of the substrate (Pope et al., 1962; Huhnke \& von Sengbusch, 1969; Fermor et al., 1985). Apparently microorganisms or their products present in compost are involved in growth stimulation.

Different groups of micro-organisms in mushroom compost are claimed to have beneficial effects on mushroom cultivation (Pope et al., 1962; Bels-Koning et al., 1962; Stanek, 1972; Chanter \& Spencer, 1974). These reports are based on descriptive rather than experimental work. Renard \& Cailleux (1973) found better growth of $A$. bisporus on straw after pre-incubation with the thermophilic fungus Scytalidium thermophilum (Cooney \& Emerson) Austwick (syn. Torula thermophila), but no effect when Humicola grisea Traaen var. thermoidea Cooney \& Emerson or Thermomyces lanuginosus Tsiklinsky (syn. Humicola lanuginosa) were used. Olivier \& Guillaumes (1979) reported better growth of $A$. bisporus on compost treated with either $S$. thermophilum or Humicola grisea var. thermoidea. Finally Ross \& Harris $(1983 a, b)$ found a faster composting process when a mixture of straw and organic nitrogen was inoculated with $S$. thermophilum or $H$. grisea var. thermoidea. This inoculation effect was not found when finished phase I compost was used because sufficient indigenous inoculum was present.

In the present study we examined the effects of various composting procedures, and the influence of $S$. thermophilum, on the growth and mushroom yield of $A$. bisporus. The growth dynamics of $S$. thermophilum during conventional and experimental composting were also investigated.

\section{METHODS}

Organisms. Commercial millet grain spawn of Agaricus bisporus strain Horst ${ }^{\circledR}$ U1 (Somycel Spawn Company, Langeais, France) was used throughout this study.

Thermophilic organisms were isolated from washed compost particles from different composting phases (see below). Relevant fungal species were Scytalidium thermophilum (Cooney \& Emerson) Austwick (syn. Torula thermophila), Myriococcum thermophilum (Fergus) van der Aa (syn. Papulaspora thermophila), and an unidentified Chaetomium species. Also Rhizomucor miehei (Cooney \& Emerson) Schipper and Talaromyces thermophilus Stolk were easily recognized. $M$. thermophilum was isolated from straw-bedded horse manure prior to composting and Chaetomium sp. from conventional phase II composting in the experimental tunnels at the Experimental Station. All fungal identifications were supervised by Dr Robert A. Samson, Centraal Bureau voor Schimmelcultures (CBS), Baarn, the Netherlands. No discrimination was made between Humicola grisea var. thermoidea, Humicola insolens and S. thermophilum. Morphological studies of our isolates and cultures from CBS, Baarn, and CAB International Mycological Institute, Kew, Surrey, UK, revealed that the isolates belonged to one aggregate taxon. Occasionally fungal colonies growing from single washed particles were subcultured. Sporulation was always of the $S$. thermophilum type. Our $S$. thermophilum strain 15.8 was mainly used in experiments with sterilized compost. This strain is deposited at CBS, Baarn, under number 671.88 .

Eleven bacterial strains, including five actinomycetes, were isolated. A particularly dominant species (as judged from our incubations), was an endospore-former tentatively identified as Bacillus licheniformis.

Compost. Experimental composts were produced in the 4-tonnes-capacity tunnels of the Experimental Station. Wetted straw-bedded horse manure was directly treated following phase II bulk procedures (Gerrits, 1987, 1988a). Conventional phase I substrate was obtained from CNC, Milsbeek.

Compost sampling. Generally about $1 \mathrm{~kg}$ of compost was randomly sampled in $100 \mathrm{~g}$ portions and mixed. Substrate in plastic trays $(56.7 \times 36.7 \times 21.5 \mathrm{~cm} ; l \times w \times h ;$ with a perforated bottom) (Utz, Schüttorf, FRG) filled with $22 \mathrm{~kg}$ of phase I compost to a height of approximately $30 \mathrm{~cm}$ was sampled from the beginning of phase II onwards. The substrate was cut vertically and sampled at distance of $6 \mathrm{~cm}$ over one vertical plane using a template. Samples of about $20 \mathrm{~g}$ were taken. In tunnels, samples of about $1 \mathrm{~kg}$ were taken at distances of $20 \mathrm{~cm}$ from only one central vertical line.

Media. In the first few experiments fresh phase II compost was used. Later, phase II compost was first dried at $70^{\circ} \mathrm{C}$, ground (10 mm mesh) (Retsch mill, Haan, FRG) and stored at room temperature. This compost was rewetted with demineralized water to $70 \%(\mathrm{v} / \mathrm{w})$ moisture. For sterilization, $100 \mathrm{~g}$ compost was autoclaved in polycarbonate culture boxes $(150 \times 105 \times 78 \mathrm{~mm}, l \times w \times h)$ (Twyford, Glastonbury, UK) for $2 \mathrm{~h}$ at $120^{\circ} \mathrm{C}$ on two successive days. Occasionally compost was checked for sterility. After sterilization ground compost was loosened with forceps.

Yeast/glucose agar [modified from Cooney \& Emerson (1964): $4 \mathrm{~g}$ bacto yeast extract (Difco), $10 \mathrm{~g}$ glucose $. \mathrm{H}_{2} \mathrm{O}, 12 \mathrm{~g}$ agar, and $1000 \mathrm{ml}$ demineralized water] was used for cultivating thermophilic organisms. Malt 
agar [10 g malt extract (L39, Oxoid), $12 \mathrm{~g}$ agar, and $1000 \mathrm{ml}$ demineralized water] was used for cultivating mushroom mycelium. Both media were autoclaved at $120^{\circ} \mathrm{C}$ for $20 \mathrm{~min}$. For selective recovery of fungi from compost particles, penicillin $\mathrm{G}\left(50 \mathrm{mg} \mathrm{l}^{-1}\right)$ and streptomycin $\left(50 \mathrm{mg} \mathrm{l}^{-1}\right)$ were added to yeast/glucose agar. For recovery of mushroom mycelium on malt agar, in addition to these bactericides, the selective fungicide benomyl (10 $\mathrm{mg}$ active ingredient $\mathrm{l}^{-1}$ ) was used.

Culture of mushroom mycelium in compost. About 25 spawn grains were put at the bottom of sterilized culture tubes $(160 \times 25 \mathrm{~mm}$ inner dimensions) as an inoculum. About $30 \mathrm{~g}$ substrate was added with forceps. Tubes were closed with prefabricated paper plugs (Steristopfen) and incubated upright at $24^{\circ} \mathrm{C}$ in the dark. Experiments were performed in triplicate. From about $5 \mathrm{~d}$ onwards the position of the mycelial front was recorded with a marker at 2-3 d intervals. When the mycelia reached the surface of the compost, marks on two opposite sides per tube were measured. Linear regression was done for values more than $30 \mathrm{~mm}$ from the site of inoculation. Growth was expressed as $G(t)=G R \times t+C$ in which $G(t)$ is growth from inoculum in $\mathrm{mm}, G R$ is growth rate in $\mathrm{mm} \mathrm{d}^{-1}, t$ is time in days, and $C$ is the intercept on the $G$ axis (point of intersection). The kinetics of adapting, i.e. accelerating, growth were not studied in detail. The influence of better air ventilation was tested using open glass cylinders instead of tubes closed at one end.

Mushroom mycelium was also grown in culture boxes containing $100 \mathrm{~g}$ substrate. Grain spawn was inoculated in a vertical profile on the narrow side of the boxes.

Culture of Scytalidium thermophilum and other thermophiles. Thermophiles were cultured on yeast/glucose agar in Petri dishes or on sterilized compost in culture boxes at $45^{\circ} \mathrm{C}$ in the dark. Compost was inoculated with six transplants of $2 \times 2 \mathrm{~mm}$ cut from a colony on an agar plate and incubated for 2 or $3 \mathrm{~d}$. This colonized substrate was used in further experiments with $A$. bisporus. Mixed cultures of $S$. thermophilum strain 15.8 and all bacterial isolates were tested. In some mixed cultures $S$. thermophilum was selectively killed by incubation of the culture box at $100^{\circ} \mathrm{C}$ in an autoclave for $10 \mathrm{~min}$ (according to Fergus \& Amelung (1971) the most resistant strains survive $68^{\circ} \mathrm{C}$ for $30 \mathrm{~min}$ or $72^{\circ} \mathrm{C}$ for $15 \mathrm{~min}$ ).

Counting of Scytalidium thermophilum and Agaricus bisporus. Compost (sub)samples of $20 \mathrm{~g}$ were blended three times for 5-10 s in $150 \mathrm{ml}$ tap water. The slurry was poured over sieves (4, 2, and $1 \mathrm{~mm}$; Endecotts, London, UK) and the remaining particles were washed vigorously with tap water (Harley \& Waid, 1955; Chang \& Hudson, 1967). Particles on the $1 \mathrm{~mm}$ sieve were collected and placed on agar plates. For each sample five plates with 10 particles were used. To count $S$. thermophilum, yeast/glucose agar (plus penicillin $\mathrm{G}$ and streptomycin) was used and plates were counted after $2 \mathrm{~d}$ incubation at $45^{\circ} \mathrm{C}$. $A$. bisporus was counted on malt agar (plus penicillin $\mathrm{G}$, streptomycin, and benomyl) after 2 weeks incubation at $24^{\circ} \mathrm{C}$. Counts were expressed as a percentage (all based on 50 particles).

Occasionally, dilutions of the blended compost slurry were pipetted into yeast/glucose agar at $45^{\circ} \mathrm{C}$ prior to plating, to count the viable spores present in compost.

Model phase II composting. Phase I compost $(50 \mathrm{~g})$ was incubated in $150 \mathrm{ml}$ beakers. To prevent drying out, water $(5 \mathrm{ml})$ was pipetted into the beakers and the substrate was placed on a nylon gauze support (controls). To test rapid $\mathrm{NH}_{3}$ removal, $1 \mathrm{M}-\mathrm{HCl}(5 \mathrm{ml})$ was used as an absorbent and replaced the water. Beakers were capped with a double layer of aluminium foil allowing limited ventilation and were incubated at $45^{\circ} \mathrm{C}$ for up to $3 \mathrm{~d}$.

Reproducibility. All experiments were repeated at least once, except those in which the effect of $S$. thermophilum strain 15.8 was tested on Agaricus arvensis, Pleurotus ostreatus and Coprinus comatus.

\section{RESULTS}

The linear growth rate of mycelium of Agaricus bisporus on compost in tubes was 8-9 mm d-1. A strict lag-phase of approximately $1 \mathrm{~d}$ was followed by a phase of accelerating growth until the mycelial front was $30 \mathrm{~mm}$ away from the site of inoculation. Subsequently growth rates were constant (Table 1; Fig. 1). Techniques allowing better gas exchange were tested. Tubes packed with compost in such a way that a ventilation channel was left along the tube wall and glass cylinders closed by plugs on both sides showed similar growth rates. When different amounts of inoculum were tested no differences in growth rates were found. However, when only one or a few spawn grains were used mycelium density was much lower initially. These density differences were not quantified. Growth rate on sterilized compost was only 3-4 $\mathrm{mm} \mathrm{d}^{-1}$. However, growth was rarely linear, but either declined with time (Fig. $1 a$ ) or was irregular (Fig. $1 b$ ). Macroscopically no differences in density were noticed between $A$. bisporus mycelium growing on compost or on sterilized compost although strands formed on sterilized compost were shorter and curly rather than linear.

Sterilized compost mixed with $1 \%$ non-sterile compost allowed a high growth rate (Table 1 ; Fig. $1 a$ ) after a considerable lag period (Table 1, low values for the calculated intercepts). When 


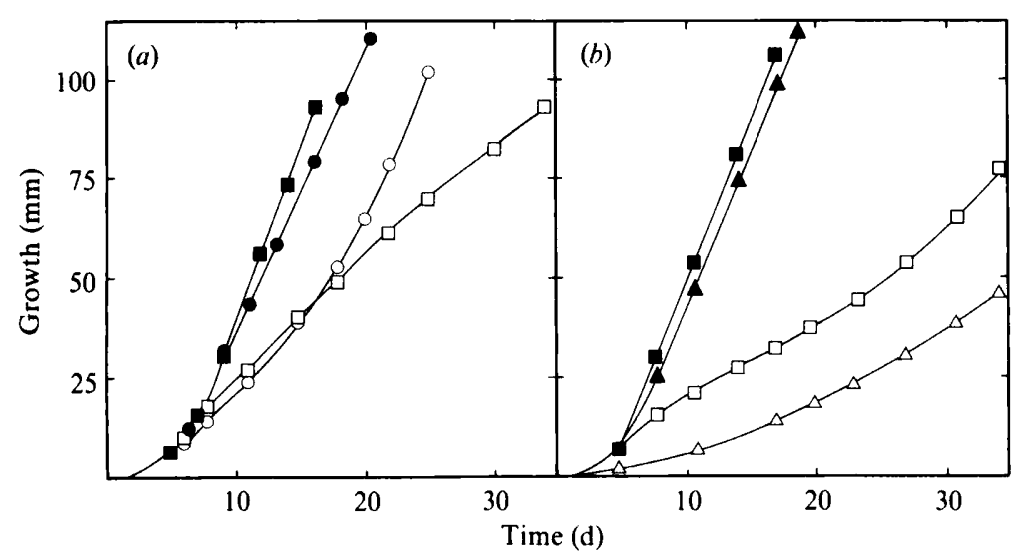

Fig. 1. Growth of $A$. bisporus mycelium on compost in test tubes. (a) $\boldsymbol{\square}$, Control 1 (untreated phase II compost); $\square$, control 2 (sterilized compost); $\bigcirc$, sterilized compost mixed with $1 \%$ untreated compost; , sterilized compost pre-incubated with $1 \%$ untreated compost at $45^{\circ} \mathrm{C}$ for $2 \mathrm{~d}$. (b) $\square, \square$, controls as in $(a) ; \Delta$, sterilized compost pre-incubated with $S$. thermophilum strain $15.8 ; \triangle$, sterilized compost preincubated with Bacillus licheniformis.

Table 1. Growth rates of A. bisporus on untreated phase II compost and sterilized phase II compost treated with $S$. thermophilum strain 15.8

$G R$ (growth rate in $\mathrm{mm} \mathrm{d}^{-1}$ ) and $C$ (intercept in $\mathrm{mm}$; 'growth' at day 0 ) were calculated by linear regression. Means and standard deviations are given; $n=$ number of 'independent' experiments (the same dried and ground compost batches or $A$. bisporus inoculum batches may be used).

\section{Compost}

$G R$ $\left(\mathrm{mm} \mathrm{d}^{-1}\right)$

$8 \cdot 6 \pm 0 \cdot 9$

$3 \cdot 2$

$7 \cdot 2+1 \cdot 0$

$7 \cdot 5 \pm 0 \cdot 8$

$7 \cdot 7 \pm 0.5$

3.0

$7 \cdot 7 \pm 0 \cdot 6$
C (intercept in $\mathrm{mm}$ )

Sterilized (note $1 a$ )

Sterilized and pre-incubated with $1 \%$ compost

Sterilized and pre-incubated with $S$. thermophilum 15.8

Dried, ground, and sterilized (note $1 b$ )

Dried, ground, sterilized and pre-incubated with

S. thermophilum 15.8

${ }^{1}$ Growth was irregular or declining (see text and Fig. 1). Growth rates were calculated for three successive measurements only. The first measurement was chosen in such a way that the highest rate is given. Because of this arbitrary choice, values for standard deviation and intercepts corresponding to the growth rates are meaningless and are not given. Growth rates were rather high (4-5 $\left.\mathrm{mm} \mathrm{d}^{-1}\right)$ in $(a)$ four experiments, $(b)$ three experiments.

${ }^{2}$ Growth rate slowly increased to the rate given in this table (as reflected in the low intercepts); not all measurements $30 \mathrm{~mm}$ in front of the inoculum could be used for linear regression.

the same mixture was incubated at $45^{\circ} \mathrm{C}$ for $2 \mathrm{~d}$ a thermophilic flora developed; fungi and actinomycetes were clearly visible. Growth rate of mushroom mycelium on this substrate was very similar to that on non-sterile compost (Table 1; Fig. $1 a$ ).

Growth of mushroom mycelium on sterilized compost pre-incubated with all isolates of the fungus Scytalidium thermophilum was almost as good as growth on non-sterile compost (Table 1; Fig. $1 b$; those data refer to strain 15.8 only). Myriococcum thermophilum and the unidentified Chaetomium species promoted growth of mushroom mycelium in the same way as $S$. thermophilum strains. Rhizomucor miehei, Talaromyces thermophilus, and some other unidentified fungal species were growth-inhibitory or indifferent. Mushroom growth on mixtures of composts pre-incubated separately with the three beneficial fungal species was similar to growth on non-mixed substrates. Bacillus licheniformis had an adverse effect on $A$. bisporus : growth was 


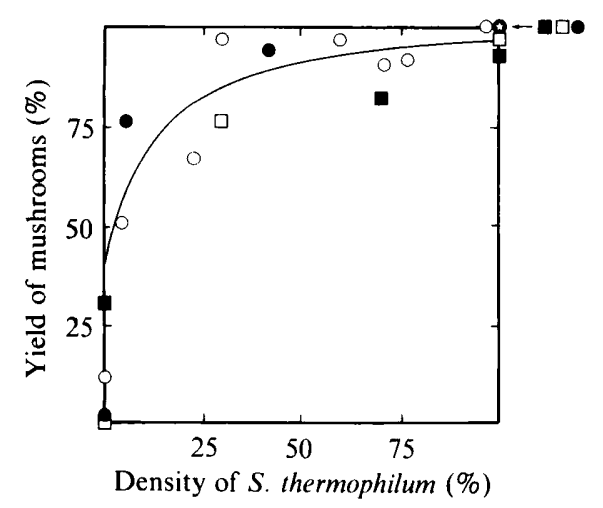

Fig. 2. Relation between yield of mushrooms and the density of $S$. thermophilum in four different runs of experimental composting: $\square$, experiment $1 ; \square, 2 ; 0,3 ; 0,4$; respectively. Yields are given as a percentage of the maximum yield (experiment 1,$246 ; 2,252 ; 3,224$; and 4, $239 \mathrm{~kg}$ fresh weight per tonne of compost, respectively). The density of $S$. thermophilum is expressed as the percentage of particles showing recovery of mycelium on agar plates. Fitted function $y=44 \cdot 2+26.5 \times \log x(y$ is yield; $x$ is density of $S$. thermophilum); coefficient of correlation is 0.85 .

slower for $12 \mathrm{~d}$ but ultimately reached the rate achieved on sterilized compost (Fig. $1 b$ ). Another 10 bacterial isolates, including five actinomycetes, were also growth-inhibitory or at best growth indifferent to $A$. bisporus. The adverse effect of the bacteria was counteracted if $S$. thermophilum strain 15.8 was also present. Treatment $\left(10 \mathrm{~min}, 100^{\circ} \mathrm{C}\right)$ of a mixed culture of $S$. thermophilum strain 15.8 and $B$. licheniformis, in which only the fungus was completely killed, showed the adverse effect of the bacterium again, with growth lagging $3 \mathrm{~d}$ behind the sterile control.

A. bisporus strain Horst ${ }^{\circledR}$ U3, Agaricus bitorquis strain Horst ${ }^{\circledR} \mathrm{K} 26$, Agaricus arvensis, Coprinus comatus and Pleurotus ostreatus all showed increased linear growth rates on sterilized compost (or straw in the case of $P$. ostreatus) treated with $S$. thermophilum strain 15.8. Growth of Lentinus edodes was not affected.

\section{Presence of Scytalidium thermophilum and Agaricus bisporus in experimental composts}

Experimental composts produced from straw-bedded horse manure in one single composting phase in experimental tunnels showed a wide range of production capacity (Gerrits, 1987) and of colonization by $S$. thermophilum. A relationship between these two parameters was calculated for values found in four composting trials (Fig. 2). The presence of other fungi was not studied in these experiments.

After inoculation and incubation of experimental composts with mushroom spawn, the densities of $S$. thermophilum and $A$. bisporus were both counted at intervals. The initial density of $S$. thermophilum of $100 \%$ was reduced to approximately $40 \%$ after $15 \mathrm{~d}$ incubation. At the same time $A$. bisporus was found on $80 \%$ of the particles from a replicate sample. After another $13 \mathrm{~d}$, $10 \mathrm{~d}$ before the appearance of mushrooms, almost all particles were colonized by $A$. bisporus but $S$. thermophilum was no longer present. In composts with low counts of $S$. thermophilum at inoculation a significant increase in density of $S$. thermophilum was observed 15 and $28 \mathrm{~d}$ after inoculation of mushroom spawn. Macroscopically these latter composts were poorly colonized by $A$. bisporus.

\section{Dynamics of Scytalidium thermophilum during conventional composting}

Twenty percent of the washed particles of straw-bedded horse manure (prior to phase I composting) contained $S$. thermophilum. However, at the end of phase I only $4 \%$ or less of the particles had $S$. thermophilum growth. Using a dilution plate technique about 500 spores per $\mathrm{g}$ fresh weight were counted at this stage. In phase II, immediately after pasteurization, $S$. thermophilum colonized particles from the centre of a tray which was the coolest part of the substrate. In contrast, at the end of phase II the central part (approx. $6 \mathrm{~cm}$ radius) was free from 
Table 2. Densities of $S$. thermophilum in model phase II composting

Densities and standard deviations are given as the percentage of particles colonized by $S$. thermophilum; values in parentheses indicate the number of replicates.

\begin{tabular}{|c|c|c|}
\hline $\begin{array}{l}\text { Incubation } \\
\text { time } \\
\text { (h) }\end{array}$ & $\begin{array}{l}\text { Control, } \\
\text { water }\end{array}$ & $\begin{array}{c}\mathrm{NH}_{3} \text { absorption } \\
\text { using } 1 \mathrm{M}-\mathrm{HCl}\end{array}$ \\
\hline \multicolumn{3}{|l|}{ Experiment I } \\
\hline 0 & $2 \quad(1)$ & (as control) \\
\hline 26 & $72 \pm 25(4)$ & $76 \pm 6(4)$ \\
\hline 34 & $90 \pm 13$ & (not determined) \\
\hline 46 & $100 \pm 0(2)$ & $99 \pm 1(2)$ \\
\hline \multicolumn{3}{|l|}{ Experiment 2} \\
\hline 0 & $2 \pm 3(2)$ & (as control) \\
\hline 18 & $9 \pm 5(4)$ & $11 \pm 5$ \\
\hline 29 & $19 \pm 12(3)$ & $51 \pm 9(4)$ \\
\hline 42 & $97 \pm 3(4)$ & $100 \pm 0(4)$ \\
\hline 52 & $100 \pm 0(4)$ & $100 \pm 0(4)$ \\
\hline
\end{tabular}

$S$. thermophilum. The centre was surrounded by a zone of another $6 \mathrm{~cm}$ which was only partially colonized. The remaining compost was fully colonized. At the end of phase II the temperature in the centre was $62{ }^{\circ} \mathrm{C}$ while the periphery was at air temperature $\left(42^{\circ} \mathrm{C}\right)$.

Sampling during phase II composting in bulk was not possible. In commercial tunnel plants $S$. thermophilum was counted at the end of the composting process in seven different batches. Densities of $S$. thermophilum were all $100 \%$ from bottom to top. In three batches the samples taken for counting were also tested in tubes for growth of $A$. bisporus. No significant differences in growth rates or lag phases between samples from any one batch were found. In composts from the small tunnels of the Experimental Station a gradient in $S$. thermophilum density was found in three out of four batches of normal phase II composting. $S$. thermophilum was found at the bottom, but it declined going upwards and at the top it was replaced by Chaetomium sp.

\section{Model phase II composting}

Finished phase I compost was incubated in $150 \mathrm{ml}$ beakers at $45^{\circ} \mathrm{C}$ and $S$. thermophilum was repeatedly counted. Densities of $S$. thermophilum increased rapidly in control beakers with water only. This increase was even faster when $\mathrm{HCl}$ was present in the beakers to absorb $\mathrm{NH}_{3}$ emanating from the compost. In this case $100 \%$ densities were reached within $48 \mathrm{~h}$. The results of two experiments given in Table 2 are representative for four of a total of six experiments. In the remaining two experiments even in the presence of $1 \mathrm{M}-\mathrm{HCl}$ full colonization was not reached within $3 \mathrm{~d}$ (data not shown). Although the effect of $1 \mathrm{M}-\mathrm{HCl}$ was not significant at any one time, in all experiments, at 14 out of 15 paired sampling times higher counts of $S$. thermophilum occurred than when water was used.

\section{Model colonization by mushroom mycelium}

Sterilized compost in culture boxes colonized by $S$. thermophilum was inoculated with mushroom grain spawn on a narrow side of the box. After $15 \mathrm{~d}$ the mycelium had grown $89 \mathrm{~mm}$ from the side of inoculation and showed a growth rate of approximately $8 \mathrm{~mm} \mathrm{~d}^{-1}$. Table 3 shows that $\boldsymbol{A}$. bisporus was present on all particles up to $75 \mathrm{~mm}$ from the side of inoculation. However, it was not recovered from every particle that was just passed by the growing mycelium. $S$. thermophilum was not recovered from particles up to $65 \mathrm{~mm}$ from the inoculum. $S$. thermophilum was still present on most particles which were recently passed by mycelium of A. bisporus.

\section{DISCUSSION}

Mushroom mycelium slowly adapted to fast growth (almost $9 \mathrm{~mm} \mathrm{~d}^{-1}$ ) on normal compost in tubes. Maximum growth rate was achieved after $30 \mathrm{~mm}$. Accelerating growth was not 
Table 3. Densities of $S$. thermophilum and A. bisporus in boxes in which A. bisporus was inoculated on one side to create a progressing front

Densities were measured as the percentage of compost particles from which mycelium was recovered on agar plates; the data presented are mean values of two boxes. Linear regression on growth data after $15 \mathrm{~d}$ incubation: $G(t)=8.2 \times t-34.4 ; G(15)=89.1 \mathrm{~mm}$.

$\begin{array}{cccc}\begin{array}{c}\text { Distance to } \\ \text { A. bisporus } \\ \text { inoculum (mm) }\end{array} & \begin{array}{c}\text { S. thermophilum } \\ \text { density }\end{array} & \begin{array}{c}\text { A. bisporus } \\ \text { density }\end{array} & \begin{array}{c}\text { Calculated age } \\ \text { of } \begin{array}{c}\text { A. bisporus } \\ \text { mycelium (d) }\end{array} \\ 0-25\end{array} \\ 25-45 & 0 & 100 & >7 \cdot 9 \\ 45-65 & 0 & 100 & 5 \cdot 5-7 \cdot 9 \\ 65-75 & 0 & 100 & 3 \cdot 0-5 \cdot 5 \\ 75-85 & 38 & 100 & 1 \cdot 8-3 \cdot 0 \\ 85-95 \text { (around front) } & 99 & 93 & 0 \cdot 6-1 \cdot 8 \\ >95 \text { (before front) } & 100 & 28 & 0 \cdot 6 \\ \end{array}$

recognized by Olivier \& Guillaumes (1979) and their growth analysis results in very low growth rates of $3 \mathrm{~mm} \mathrm{~d}^{-1}$. In commercial cultivation, mushroom mycelium probably never reaches the maximum growth rate. When spawn grains are distributed evenly through compost their mutual distance is approximately $2 \mathrm{~cm}$ (calculated from standard inoculum rates). Therefore compost could be fully colonized at an early stage although the incubation period used is about $12 \mathrm{~d}$.

The effect of $S$. thermophilum on growth rate of mushroom mycelium in sterilized compost is quite remarkable. Radial growth rate of mushroom mycelium on any laboratory medium never exceeds $3 \mathrm{~mm} \mathrm{~d}^{-1}$ (Last et al., 1974; re-calculated from diameter measurements). We hypothesize that $S$. thermophilum provides a trigger for enhanced growth of $A$. bisporus acting by an unknown mechanism. If a non-volatile growth substance is involved, this substance is apparently labile on autoclaving. However, the rather exceptional growth rates of 4-5 $\mathrm{mm} \mathrm{d}^{-1}$ in some experiments with sterilized compost (notes to Table 1) could be explained by the suboptimal presence of a growth factor in these particular batches of compost. Unfortunately a growth-promoting effect of $S$. thermophilum on $A$. bisporus is not found on agar media (Renard \& Cailleux 1973). This could be a major problem in elucidating the growth-promoting effect.

Enhanced growth caused by $S$. thermophilum is not species specific. Other thermophilic fungi, i.e. Chaetomium sp. and Myriococcum thermophilum, had similar effects and also different species of mushrooms were affected, i.e. A. bitorquis, A. arvensis, Coprinus comatus and Pleurotus ostreatus. It would be interesting to investigate the existence of similar relationships between mycelia of mushrooms and thermophilic(?) organisms in nature, e.g. in temperate grassland soils. Thermophilic fungi are widely distributed in these habitats (Apinis, 1972). Perhaps the observations of Thompson \& Rayner (1983) on growth of some woodland soil fungi in sterilized and unsterile soil relate to the same phenomenon.

In mixed cultures, adverse effects on mushroom growth by bacteria such as $B$. licheniformis were counteracted by the presence of $S$. thermophilum, indicating its presence to be important for compost selectivity. Actinomycetes and other bacteria might play a role in successful $S$. thermophilum colonization during composting. Till (1962) showed that good yields of mushrooms can be produced on a non-composted sterile mixture containing mainly straw and organic nitrogen. Therefore speculations on an indispensable contribution of $S$. thermophilum to the nutrition of mushroom mycelium have no grounds. $S$. thermophilum is important only for compost selectivity and fast colonization by $A$. bisporus.

Occasionally good yields of $A$. bisporus were obtained at moderate densities of $S$. thermophilum in experimental composts (Fig. 2). Apparently complete colonization of compost is not strictly required before the composting process can be stopped. A continuing development of $S$. thermophilum was found in experimental composts with low initial densities after inoculation with mushroom grain spawn and incubation at $24^{\circ} \mathrm{C}$. Similarly a growth-promoting trigger for A. bisporus, i.e. S. thermophilum, slowly developed at $24^{\circ} \mathrm{C}$ in sterilized compost that had been 
mixed with $1 \%$ normal compost (Table 1 ; Fig. 1 a). Mesophilic growth down to $20^{\circ} \mathrm{C}$ was found in vitro for the isolated $S$. thermophilum strains (unpublished results).

Very low yields of $A$. bisporus linked to low densities of $S$. thermophilum (Fig. 2) might be explained by non-selective and/or toxic properties of experimental composts. Non-selectivity could result from direct action of actinomycetes and other bacteria not counteracted by $S$. thermophilum. On the other hand, composts could have been toxic because of high $\mathrm{pH}$ and $\mathrm{NH}_{4}^{+}$ values (Gerrits, 1987), which normally result in excessive amounts of volatile $\mathrm{NH}_{3}$ (Gerrits, 1977). A negative effect of unchecked bacteria by volatilizing $\mathrm{NH}_{3}$ can not be excluded.

Our data show that $S$. thermophilum is already present in the beginning of phase I. The inoculum might have originated from cereal straw (Chang \& Hudson, 1967). At the end of phase I $S$. thermophilum is hardly present in active form but mainly as dormant spores. For its development phase I is superfluous. S. thermophilum gradients were found at the end of phase II in trays in mushroom houses but not in normal commercial tunnels. Also temperature gradients in trays are more distinctive than in tunnels (Gerrits, 1988b). Apparently process control in thick compost layers in tunnels by forced air movement through the body of the compost is very adequate. Interestingly, Randle \& Smith (1985) found gradients in mushroom production capacity in a tunnel. Successful treatment of raw ingredients in tunnels omitting phase I (Perrin \& Gaze, 1987; Gerrits, 1987) might be explained by maintenance of near-optimal conditions for $S$. thermophilum development. Those conditions are hardly maintained in raw materials in trays in mushroom houses (Lambert, 1941).

In beakers phase I compost was colonized by $S$. thermophilum in $2 \mathrm{~d}$ (Table 2). This period is similar to that required to reach a compost free of $\mathrm{NH}_{3}$ in the laboratory experiments of Ross \& Harris (1982). In commercial practice phase II takes 8-9 d. This discrepancy in time cannot be explained by a rate-limiting inoculum level of $S$. thermophilum (see also Ross \& Harris, $1983 b$ ). We found a faster colonization in beakers when $1 \mathrm{M}-\mathrm{HCl}$ was used as an $\mathrm{NH}_{3}$ absorbent, compared to controls with water only (Table 2). Compost colonization by $S$. thermophilum might be limited by ammonification or a slow removal, or assimilation, of $\mathrm{NH}_{3}$. This fits well to the conclusions of Gerrits (1979) and Ross \& Harris (1982) that a longer phase II is required when $\mathrm{NH}_{3}$ levels in phase I compost are higher.

$S$. thermophilum was not recovered from particles on agar plates $28 \mathrm{~d}$ after inoculation of experimental composts with $A$. bisporus. Such a disappearance was also found by Olivier $\&$ Guillaumes (1979). As mentioned above, S. thermophilum survives at mesophilic temperatures. Therefore the data in Table 3 can only be explained by the inactivation of $S$. thermophilum $3 \mathrm{~d}$ after passage of $A$. bisporus mycelium. It remains unclear whether growth promotion of $A$. bisporus by $S$. thermophilum and inactivation of $S$. thermophilum by $A$. bisporus are linked phenomena.

We conclude the following: (1) the presence of $S$. thermophilum is important for successful colonization of compost by mushroom mycelium, and (2) the pre-colonization of mushroom compost by $S$. thermophilum is a key factor of phase II composting, resulting in a selective substrate. The composting process might thus be optimized by aiming at optimal conditions for growth of $S$. thermophilum. The temperatures should be close to $45^{\circ} \mathrm{C}$ (Rosenberg, 1975) and excessive levels of free $\mathrm{NH}_{3}$ should be avoided (see above). A 'tunnel' system is adequate to produce compost omitting phase I (Perrin \& Gaze, 1987; Gerrits, 1987). Apparently nearoptimal conditions can be maintained even in non-composted substrates very susceptible to self heating. When straw-bedded horse manure and wheat straw are used as ingredients, inoculation with $S$. thermophilum will not be useful.

\section{REFERENCES}

APINIS, A. E. (1972). Thermophilous fungi in certain grasslands. Mycopathologia et mycologia applicata $\mathbf{4 8 ,}$ 63-74.

Bels-Koning, H. C., Gerrits, J. P. G. \& VaANDRAGER, M. H. (1962). Some fungi appearing towards the end of composting. Mushroom Science 5, 165-169.

Chang, Y. \& Hudson, H. J. (1967). The fungi of wheat straw compost I. Ecological studies. Transactions of the British Mycological Society 50, 649-666.

Chanter, D. P. \& Spencer, D. M. (1974). The importance of thermophilic bacteria in mushroom compost fermentation. Scientia horticulturae 2, 249256. 
CoOney, D. G. \& EMERSON, R. (1964). Thermophilic Fungi. San Francisco: Freeman.

DERKS, G. (1973). 3-phase-1. Mushroom Journal 9, 396403.

Fergus, C. L. \& Amelung, R. M. (1971). The heat resistance of some thermophilic fungi on mushroom compost. Mycologia 63, 675-679.

Fermor, T. R., RANdle, P. E. \& SMith, J. F. (1985). Compost as a substrate and its preparation. In The Biology and Technology of the Cultivated Mushroom, pp. 81-109. Edited by P. B. Flegg, D. M. Spencer \& D. A. Wood. Chichester: Wiley.

Gerrits, J. P. G. (1977). The significance of gypsum applied to mushroom compost, in particular in relation to the ammonia content. Netherlands Journal of Agricultural Science 25, 288-302.

GERRITS, J. P. G. (1979). Influence of pH and ammonia in mushroom compost. Mushroom Science 10, 15-29.

GERRITS, J. P. G. (1987). Biedt composteren in tunnels perspectief? De Champignoncultuur 31, 357-365.

Gerrits, J. P. G. (1988a). Compost treatment in bulk for mushroom growing. Mushroom Journal 182, 471 475.

GerRITS, J. P. G. (1988b). Nutrition and compost. In The Cultivation of Mushrooms, pp. 29-72. Edited by L. J. L. D. van Griensven. Rustington: Darlington Mushroom Laboratories Ltd.

Harley, J. L. \& WAID, J. S. (1955). A method of studying active mycelia on living roots and other surfaces in the soil. Transactions of the British Mycological Society 38, 104-118.

HuhnKe, W. \& Von Sengbusch, R. (1969). Champignonanbau auf nicht kompostiertem Nahrsubstrat. Mushroom Science 7, 405-419.

Laborde, J., Olivier, J. M., Houdeau, G. \& DELPECH, P. (1987). Indoor static composting for mushroom (Agaricus bisporus Lange Sing) cultivation. In Cultivating Edible Fungi (Developments in Crop Science vol. 10), pp. 91-100. Edited by P. J. Wuest, D. J. Royse \& R. B. Beelman. Amsterdam Elsevier.

LAMBERT, E. B. (1941). Indoor composting for mushroom culture. Circular no. 609 (15 pp.) Washington : USDA.

Last, F. T., Hollings, M. \& Stone, O. M. (1974). Effects of cultural conditions on the mycelial growth of healthy and virus-infected cultivated mushroom, Agaricus bisporus. Annals of Applied Biology 76, 99111.
Olivier, J. M. \& Guillaumes, J. (1979). Evolution microbiologique des composts pendant la croissance mycelienne du champignon de couche. Mushroom Science 10, 311-334.

Perrin, P. S. \& Gaze, R. H. (1987). Controlled environment composting. Mushroom Journal 174, 195-197.

PoPe, S., Knaust, H. \& Knaust, K. (1962). Production of compost by thermophilic fungi. Mushroom Science 5, 123-126.

Randle, P. E. \& SMith, J. F. (1985). Mushroom compost variability in phase II. Mushroom Journal 150, 206-210.

Renard, Y. \& Cailleux, R. (1973). Contribution á l'étude des microorganismes du compost destiné á la culture du champignon de couche. Revue de mycologie 37, 36-47.

Rosenberg, S. L. (1975). Temperature and pH optima for 21 species of thermophilic and thermotolerant fungi. Canadian Journal of Microbiology 21, 15351540.

Ross, R. C. \& Harris, P. J. (1982). Some factors involved in phase II of mushroom compost preparation. Scientia horticulturae 17, 223-229.

Ross, R. C. \& HARRIS, P. J. (1983a). An investigation into the selective nature of mushroom compost. Scientia horticulturae 19, 55-64.

Ross, R. C. \& Harris, P. J. (1983b). The significance of thermophilic fungi in mushroom compost preparation. Scientia horticulturae 20, 61-70.

SINDEN, J. W. \& HAUSER, E. (1950). The short method of composting. Mushroom Science 1, 52-59.

STANEK, M. (1972). Microorganisms inhabiting mushroom compost during fermentation. Mushroom Science 8, 797-811.

Thompson, W. \& RAYNer, A. D. M. (1983). Extent, development and function of mycelial cord systems in soil. Transactions of the British Mycological Society 81, 333-345.

TILL, O. (1962). Champignonkultur auf sterilisiertem Nährsubstrat und die Wiederverwendung von abgetragenem Kompost. Mushroom Science 5, 127-133.

TSCHIERPE, H. J. (1983). Environmental factors and mushroom strains. Mushroom Journal 132, 422.

WOOD, D. A. \& FERMOR, T. R. (1985). Nutrition of Agaricus bisporus. In The Biology and Technology of the Cultivated Mushroom, pp. 43-61. Edited by P. B. Flegg, D. M. Spencer \& D. A. Wood. Chichester: Wiley. 